\title{
Factors and Pattern of Injuries Associated with Road Traffic Accidents in Hilly District of Nepal
}

\author{
Vijaya Laxmi Shrestha1, Dharma Nand Bhatta2,3, Krishna Man Shrestha4, Krishna Bahadur GC5, \\ Sudarshan Paudel ${ }^{*}$
}

\author{
${ }^{1}$ Department of Public Health, Hope International College, Purbanchal University, Lalitpur, Nepal \\ ${ }^{2}$ Department of Public Health, Nobel College, Pokhara University, Kathmandu, Nepal \\ ${ }^{3}$ Faculty of Medicine, Epidemiology Unit, Prince of Songkla University, Hatyai, Thailand \\ ${ }^{4}$ School of Public Health and Community Medicine, The University of New South Wales, Sydney, Australia \\ ${ }^{5}$ School of Public Health, Patan Academy of Health Sciences, Lalitpur, Nepal \\ Email: *sudarshanpaudel@gmail.com
}

How to cite this paper: Shrestha, V.L., Bhatta, D.N., Shrestha, K.M., GC, K.B. and Paudel, S. (2017) Factors and Pattern of Injuries Associated with Road Traffic Accidents in Hilly District of Nepal. Journal of Biosciences and Medicines, 5, 88-100. https://doi.org/10.4236/jbm.2017.512010

Received: November 11, 2017

Accepted: December 11, 2017

Published: December 14, 2017

Copyright $\odot 2017$ by authors and Scientific Research Publishing Inc. This work is licensed under the Creative Commons Attribution International License (CC BY 4.0).

http://creativecommons.org/licenses/by/4.0/

\begin{abstract}
Introduction: In $21^{\text {st }}$ century, road traffic accidents (RTA) are considered as increasing epidemic of non-communicable disease which is abandoned and needs special attention to prevent them. The aim of this study was to assess the factors and pattern of injuries associated with road traffic accidents. Methods: A cross sectional study was conducted among 112 RTA victims and 56 drivers in Palpa District of Nepal. The association of factors and pattern of injuries with exposure to accidents was assessed using Fisher's exact test. Bivariate logistic regression examined the association between driving and socio-demographics factors and exposure to road accidents. Results: Of 112 RTA victims, $50 \%$ were in the age group of 21 to 40 years and $71.4 \%$ were male. Drivers who were in the age less than or equal to 30 years were more likely (OR: $3.6 ; 95 \%$ CI: $1.0,14.3$ ) to expose to an accident than those who were above 30 years. Similarly, those having driving speed less than $40 \mathrm{~km} / \mathrm{hr}$ were less likely to expose to an accident than those with speed $40-60 \mathrm{~km} / \mathrm{hr}$ (OR: 6.0; 95\% CI: $0.8,73.5$ ) and those with speed more than $60 \mathrm{~km} / \mathrm{hr}$ (OR 7.8; 95\% CI: 1.0, 100.1). Moreover, the driving experience was also found positively associated (OR: 5.6 ; 95\% CI: 1.1, 35.5) with the exposure to an accident. Conclusion: Being in younger age group, male gender, morning time, the driving speed, driving experiences, and driving hours on the road were positively associated with RTA. The efforts should be made to enforce laws in control of speed targeting experienced drivers and those with younger age groups.
\end{abstract}

\section{Keywords}

Road Traffic Accidents, Factors, Pattern of Injuries, Driver, Prevention and 
Awareness

\section{Introduction}

Globally, road traffic accidents (RTA) are common public health problem and established as the eighth leading cause of death which have similar impact as other communicable and non-communicable diseases [1]. Around 1.24 million people have unnatural deaths and 20 to 50 million people suffer with non-fatal injuries due to road traffic injuries in the world [2] [3]. The global trends of road traffic accidents will become a fifth leading cause of death by 2030 [2] [3]. The global economic burden caused by RTA was 518 billion USD [4]. Further, 100 billion USD and $1 \%-2 \%$ of their gross national product has estimated to economic loss due to road traffic accidents in low and middle income countries alone [5]. Approximately $91 \%$ of the world's victims on the road accident have occurred in low and middle income countries [3]. In developing world, about 186,300 children under the age 18 die due to RTAs in a year, which is three times greater than developed countries [6]. One of the systematic review on road traffic injuries in Nepal showed that the mortality rate due to traffic has rose from 4 per 100,000 population in 2001-2002 to 7 per 100,000 in 2011-2012 [7]. However, status paper on road safety in Nepal depicts that fatality rate has dropped from 17 to 12 per 10,000 registered vehicles from 2009 to 2012 [8]. According to WHO report in 2011, injuries due to RTA in Nepal constitutes $1.7 \%$ of total mortality. Similarly, the country has lost $0.8 \%$ of GDP due to road traffic accident [3].

In most of the developing and developed countries, RTAs are increasing day by day leading to injuries, disabilities and deaths. The most common risk factors associated with RTA are over speed, driving under influence, not using safety measures such as seat belts, helmets and child restraints [3] [9] [10] [11]. In addition, poorly constructed roads, increased number of vehicles that are poorly maintained, unplanned urbanization and industrialization, motorization, overpopulation and fragile traffic rules were the leading causes of increasing road accidents in the developing countries [9] [11] [12] [13]. One of the highly dangerous roads around the world is found in Nepal with the possibility of road accidents that is 100 and 10 times greater than in Japan and India simultaneously [14]. Moreover, age of the driver, driving time and geographical location of driving are also responsible factors for RTA [9] [15]. The frequently vulnerable groups of RTAs are pedestrians [16], motorcyclists, bicyclists, scooter riders, children and elderly people. The most of the accidents are unnatural and easily preventable [15], in which vehicle condition and environmental factors are accountable to the RTAs [17].

Among the various injuries resulted from RTAs, head is the most commonly affected site among the victims [15] [18] [19] [20] which is then followed by upper limbs and lower limbs [20]. Along with the head injuries such as skull fracture, subdural haemorrhages, frontal bone fracture; liver lacerations and ribs 
fracture are found as common injuries [19]. Lacerations, abrasions and bruises are the most common forms of external injuries whereas fractures, chest injury, abdominal injury are the internal types of injuries among RTA victims [20]. However, the common site of fracture is lower limbs followed by upper limbs and then skull bones [20]. The accidents are reported high at night and among automobile accidents [21].

Geographical variations are unique in Nepal where the knowledge related to road safety and road constructions are comparatively poor in Nepal. RTAs related factors and patterns of injuries related literatures are sparse in Nepal. Therefore, this study aimed to assess the factors and patterns of injuries related to RTAs.

\section{Methods}

\subsection{Research Settings and Participants}

A cross-sectional study was conducted in Palpa District of Nepal among road traffic victims and drivers. Study setting district has two reputed largest referral level hospital targeted for ten districts of western region of Nepal. Furthermore, the district was connected with three low-mid-and-high land geographical regions where the road traffic injuries were common. Next, low cost specialized services are available in the hospitals for all the patients. RTAs victims were taken from United Mission Hospital and Lumbini Medical College \& Research Centre and the drivers from bus/jeep station were selected by using consecutive sampling technique. Only respondents who were agreed and gave their informed consent were included in the study. Victims injured by any motorized vehicles and drivers of both private and public four or six wheelers were included in the study. Further, respondents who were unable to speak and have fatal injuries were excluded from the study. Interviews were carried out separately in a suitable setting in the hospital, commonly where the respondent felt comfortable, by trained enumerators. Total 112 victims and 56 drivers were interviewed for data collection.

\subsection{Sampling and Sample Size Calculation}

The World Health Statistics published by World Health Organization South East Asian Regional Organization in 2010 [WHO-SEAR 2010] has revealed $8.8 \%$ of total mortality due to injuries and out of total $90 \%$ contributed by RTI. Hence, total burden of RTI is $7.92 \%$. With this reference, the sample size was calculated as 111 . We added one respondent to make it even so that number of drivers was calculated as $56(50 \%$ of 112$)$.

\subsection{Sampling Technique}

Multistage sampling technique was used. Palpa District, a hilly district in central part of Nepal was selected purposely in the first stage. In the second stage, two hospitals namely; United Mission Hospital and Lumbini Medical College \& Research Centre, Palpa were selected purposely. In third stage, accident cases (vic- 
tims) attending these hospitals were taken as first category respondents till the required sample was met.

Drivers of four and six wheeler were taken as second category respondents. They were selected from four "bus/jeep stations" and from each station 14 drivers were taken. First come first interviewed method was applied for the drivers till the required sample was met.

\subsection{Data Collection and Measures}

A structured questionnaire was used throughout face-to-face interview. The data collection tools were firstly developed in English version and later translated into Nepali. Another connected district was selected for pre-testing of the questionnaires and after the pre-testing, required changes in the tools was incorporated.

Written informed consent was taken from the respondents before they were interviewed for data collection. Participation in the study for all the respondents was completely volunteered. Privacy, anonymity and right to withdraw were ensured before they were enrolled in the study. Institutional approval was taken from the both hospitals. The Department of Public Health, Hope International College, had reviewed and approved this study.

Socio-demographic measures included were age at interview, monthly income, education, employment status of victims. Further, education was coded as illiterate (unable to read and write), literate (able to read and write without formal education), primary education (up to five years schooling), secondary and higher secondary (education of schooling from six to twelve years), and above higher secondary (education more than twelve years). Employment status was dichotomized as formal (who have formal appointment letter) and informal employment (who have no formal appointment letter).

Information related to pattern of RTAs with victims were measured by using day of accidents, time of accidents, place of accidents, vehicle types, mode of travel during accidents, type of accidents, causes of accidents, type of injury, pattern of injury and cost of treatment.

Vehicle drivers' exposure and factors related to RTAs variables have been measured as history of exposure (coded as yes and no), age, education, residence, speed, job experience, daily working hours, insurance and ownership of vehicle.

\subsection{Data Analysis}

We estimated the proportion of the study variables of interest (patterns of injury, factors related to injury). We used Fisher's exact test to determine significant differences between demographic variables and RTA exposure. Bivariate logistic regression was applied and odds ratio (OR) with 95\% confidence interval was presented. SPSS version 20 software was used (SPSS Inc., Chicago, IL, USA) for data analysis.

\section{Results}

Table 1 shows that half (50\%) of the victims represented the age group $21-40$ 
Table 1. Demographic characteristics of victims $(n=112)$.

\begin{tabular}{ccc}
\hline Characteristics & $\mathbf{n}(\%)$ & 95\% CI \\
\hline $\begin{array}{c}\text { Age in years } \\
\leq 20\end{array}$ & $38(34.0)$ & $25.2,43.5$ \\
$21-40$ & $56(50.0)$ & $40.4,59.6$ \\
$>40$ & $18(16.0)$ & $9.8,24.2$ \\
Sex & & \\
Male & $80(71.4)$ & $62.1,79.6$ \\
Female & $32(28.6)$ & $20.4,37.9$ \\
Education level & & \\
Illiterate to primary & $40(35.7)$ & $26.9,45.3$ \\
Secondary to higher secondary & $63(56.2)$ & $46.5,65.6$ \\
Graduate and above & $9(8.1)$ & $3.7,14.7$ \\
Occupation & & \\
Formal employment & & $15.0,31.2$ \\
Informal employment & $25(22.3)$ & $68.8,85.0$ \\
\hline
\end{tabular}

years and 34\% were below 20 years. Majority $(71.4 \%)$ of the victims were male. More than half $(56.2 \%)$ of the victims were educated from secondary to higher secondary level of education. Furthermore, our finding revealed that three fourth $(77.7 \%)$ of the RTA victims have informal employment.

Table 2 shows that the highest number of accidents took place on Saturdays $(33 \%)$ and $50 \%$ of the accidents were in the morning ( $6.00 \mathrm{am}-12.00 \mathrm{pm})$ time followed by $31.2 \%$ in between $12.00 \mathrm{pm}$ to $6.00 \mathrm{pm}$. Majority (69\%) of accidents were in the highway areas. Nearly two fifth (38.4\%) of the accidents were caused by two wheeler vehicles and $36.6 \%$ were with four wheelers. The passengers (55.4\%) and bike riders (29.5\%) were the main victims of RTAs. Collision between two motorized vehicles $(26.8 \%)$ was found the major type of accident. However, negligence of driver (42\%) and poor vehicle condition (24.1\%) were the major causes of the accident as reported by the victims. Findings showed that half $(50.9 \%)$ of the victims had minor injury, $42 \%$ had moderate and $7.1 \%$ had severe injury. The patterns of injuries among victims were as follows: maximum number $(41.1 \%)$ of the victims had head injuries, $39.3 \%$ had cut injuries and 25.8\% had fractures. Among the total fractures, lower extremities were the commonest site. Regarding the cost of injuries, $57.1 \%$ of them have expensed less than or equal to NPR 5000 whereas 30.4\% have expensed above NPR 20000.

Table 3 shows the factors associated with exposure to accidents with different characteristics of drivers. Drivers who were aged less than or equal to 30 years were more likely (OR: 3.6; 95\% CI: 1.0, 14.3) to have exposed with accident than those who were above 30 years. Those who have driving speed more than or equal $40-60 \mathrm{~km} / \mathrm{hr}$ (OR: 6.0; 95\% CI: 0.8, 73.5) and more than or equal $60 \mathrm{~km} / \mathrm{hr}$ 
Table 2. Information related to pattern of RTAs among victims $(n=112)$.

\begin{tabular}{|c|c|c|}
\hline Characteristics & n (\%) & $95 \% \mathrm{CI}$ \\
\hline \multicolumn{3}{|l|}{ Day of accident } \\
\hline Sunday & $13(11.6)$ & $6.3,19.0$ \\
\hline Monday & $16(14.3)$ & $8.4,22.2$ \\
\hline Tuesday & $10(8.9)$ & $4.4,15.8$ \\
\hline Wednesday & $16(14.3)$ & $8.4,22.2$ \\
\hline Thursday & $7(6.3)$ & $2.5,12.4$ \\
\hline Friday & $13(11.6)$ & $6.3,19.0$ \\
\hline Saturday & $37(33.0)$ & $24.4,42.5$ \\
\hline \multicolumn{3}{|l|}{ Time of accident } \\
\hline$>00: 00-06: 00 \mathrm{hr}$ & $6(5.4)$ & $2.0,11.3$ \\
\hline$>06: 00-12: 00 \mathrm{hr}$ & $56(50.0)$ & $40.4,59.6$ \\
\hline$>12: 00-18: 00 \mathrm{hr}$ & $35(31.2)$ & $22.8,40.7$ \\
\hline$>18: 00-24: 00 \mathrm{hr}$ & $15(13.4)$ & $7.7,21.1$ \\
\hline \multicolumn{3}{|l|}{ Place of accident } \\
\hline Highway area & $77(68.8)$ & $59.3,77.2$ \\
\hline Other area & $35(31.2)$ & $22.8,40.7$ \\
\hline \multicolumn{3}{|l|}{ Vehicle types } \\
\hline 2 wheeler & $43(38.4)$ & $29.3,48.0$ \\
\hline 4 wheeler & $41(36.6)$ & $27.7,46.2$ \\
\hline 6 wheeler & $28(25.0)$ & $17.3,34.1$ \\
\hline \multicolumn{3}{|l|}{ Mode of travel during accident } \\
\hline Bike rider & $33(29.5)$ & $21.2,38.8$ \\
\hline Passenger & $62(55.4)$ & $45.7,64.7$ \\
\hline Pedestrian & $8(7.1)$ & $3.1,13.6$ \\
\hline Others & $9(8.0)$ & $3.7,14.7$ \\
\hline \multicolumn{3}{|l|}{ Type of accident } \\
\hline Collision between vehicles & $30(26.8)$ & $18.8,36.0$ \\
\hline Fell down & $22(19.6)$ & $12.7,28.2$ \\
\hline Collision with pedestrians & $14(12.5)$ & $7.0,20.0$ \\
\hline Sideways collision & $15(13.4)$ & $7.7,21.1$ \\
\hline Self motorbike accident & $25(22.3)$ & $15.0,31.1$ \\
\hline Others & $6(5.4)$ & $2.0,11.3$ \\
\hline \multicolumn{3}{|l|}{ Causes of accident } \\
\hline Drivers' fault/negligence & $47(42.0)$ & $32.7,51.7$ \\
\hline Inappropriate road construction & $18(16.1)$ & $9.8,24.2$ \\
\hline Poor vehicle condition & $27(24.1)$ & $16.5,33.1$ \\
\hline Others & $20(17.8)$ & $11.3,26.2$ \\
\hline \multicolumn{3}{|l|}{ Type of injury } \\
\hline Minor & $57(50.9)$ & $41.3,60.5$ \\
\hline Moderate & $47(42.0)$ & $32.7,51.7$ \\
\hline Severe & $8(7.1)$ & $3.1,13.6$ \\
\hline
\end{tabular}


Continued

\begin{tabular}{ccc}
\hline Pattern of injury & & \\
Head injury & $46(41.1)$ & $31.9,50.8$ \\
Fracture & $29(25.9)$ & $18.1,35.0$ \\
Spinal injury & $2(1.8)$ & $0.2,6.3$ \\
Cut injury/sprain & $35(31.2)$ & $22.8,40.7$ \\
Cost of treatment in NPR & & \\
$\leq 5000$ & $64(57.1)$ & $47.4,66.4$ \\
$>5000-20,000$ & $14(12.5)$ & $7.0,20.1$ \\
$>20,000$ & $34(30.4)$ & $22.0,39.8$ \\
\hline
\end{tabular}

Table 3. Factors associated with exposure to RTAs among drivers $(n=56)$.

\begin{tabular}{|c|c|c|c|c|}
\hline \multirow{2}{*}{ Characteristics } & \multicolumn{2}{|c|}{ Exposure to accident } & \multirow{2}{*}{ Odds ratio } & \multirow{2}{*}{ p-value } \\
\hline & Yes $(n=36)$ & No $(n=20)$ & & \\
\hline \multicolumn{5}{|l|}{ Age in years } \\
\hline$\leq 30$ & $22(61.1)$ & $6(30.0)$ & $3.6(1.0,14.3)$ & 0.05 \\
\hline$>30$ & $14(38.9)$ & $14(70.0)$ & Reference & \\
\hline \multicolumn{5}{|l|}{ Education level } \\
\hline Illiterate to primary & $12(33.3)$ & $8(40.0)$ & $0.8(0.2,2.7)$ & 0.77 \\
\hline Secondary and above & $24(66.7)$ & $12(60.0)$ & Reference & \\
\hline \multicolumn{5}{|c|}{ Average driving speed in highway } \\
\hline$<40 \mathrm{~km} / \mathrm{h}$ & $2(5.6)$ & $6(30.0)$ & Reference & \\
\hline $40-60 \mathrm{~km} / \mathrm{h}$ & $17(47.2)$ & $8(40.0$ & $6.0(0.8,73.5)$ & 0.05 \\
\hline$\geq 60 \mathrm{~km} / \mathrm{h}$ & $17(47.2)$ & $6(30.0)$ & $7.8(1.0,100.1)$ & 0.03 \\
\hline \multicolumn{5}{|l|}{ Residence } \\
\hline Rural & $16(44.4)$ & $7(35.0)$ & $1.5(0.4,5.5)$ & 0.58 \\
\hline Urban & $20(55.6)$ & $13(65.0)$ & Reference & \\
\hline \multicolumn{5}{|l|}{ Job started from helper } \\
\hline Yes & $26(72.2)$ & $12(60.0)$ & $0.6(0.1,2.2)$ & 0.38 \\
\hline No & $10(27.8)$ & $8(40.0)$ & Reference & \\
\hline \multicolumn{5}{|c|}{ Driving experiences in year } \\
\hline$\leq 5$ & $6(16.7)$ & $11(55.0)$ & Reference & \\
\hline $5-10$ & $13(36.1)$ & $4(20.0)$ & $5.6(1.1,35.5)$ & 0.04 \\
\hline$>10$ & $17(47.2)$ & $5(25.0)$ & $5.9(1.3,32.5)$ & 0.01 \\
\hline \multicolumn{5}{|c|}{ Average hour of driving/day } \\
\hline$\leq 5$ & $8(22.2)$ & $11(55.0)$ & Reference & \\
\hline $5-10$ & $13(36.1)$ & $5(25.0)$ & $3.4(0.7,18.0)$ & 0.09 \\
\hline$>10$ & $15(41.7)$ & $4(20.0)$ & $4.9(1.0,28.7)$ & 0.04 \\
\hline \multicolumn{5}{|l|}{ Vehicle insurance } \\
\hline Yes & $33(91.7)$ & $16(80.0)$ & Reference & \\
\hline No & $3(8.3)$ & $4(20.0)$ & $0.4(0.1,2.5)$ & 0.23 \\
\hline \multicolumn{5}{|l|}{ Ownership of vehicle } \\
\hline Own & $9(25.0)$ & $11(55.0)$ & Reference & \\
\hline Private company & $27(75.0)$ & $9(45.0)$ & $3.6(1.0,13.7)$ & 0.04 \\
\hline
\end{tabular}


(OR; 7.8; 95\% CI: 1.0, 100.1) were more likely to have exposed with accident than those who have driving speed less than $40 \mathrm{~km} / \mathrm{hr}$. Drivers who were from rural area were less likely (OR: 1.5; 95\% CI: $0.4,5.5)$ to have exposed with accident than those from urban area. Drivers who were experienced from 5 to 10 years were 5.6 times (95\% CI: 1.1, 35.5) and those experienced greater than 10 years were 5.9 times $(1.3,32.5)$ more likely to have exposed with accident than those who were experienced less than or equal to 5 years. Similarly, the drivers who were engaged in driving greater than 10 hours a day were more likely (OR: 4.9; 95\% CI: 1.0, 28.7) to have exposed with accident than those who were engaged in driving less than or equal 5 hours a day. Moreover, the drivers who drive private company vehicle were more likely (OR: 3.6; 95\% CI: $1.0,13.7$ ) to have exposed with an accident than those who drive own vehicles.

The study found differences between the level of awareness of drivers and victims about RTAs. In driver's opinion, old and poor condition of the vehicles was reported to be a major cause of RTAs whereas over speed was the major cause of RTAs in victim's opinion. Nearly three fourth (69\%) of the drivers and one third (32.1\%) of the victims reported awareness and training for drivers were necessary to reduce RTAs. One fourth(25.5\%) of the drivers reported that strong traffic rules and proper maintenance of vehicles could reduce RTAs while $13.4 \%$ of the victims reported that avoiding overload of passengers and driving under influence of alcohol could reduce the RTAs (data not shown).

\section{Discussion}

This study has illustrated the factors responsible for road traffic accidents and the patterns of the injuries among RTAs victims. Our study has tried to explore the opinions related to RTAs from both drivers and victims. Similarly, the study has shown the association between different factors and exposure to accidents.

This study revealed that RTAs exposure was significantly associated with young aged drivers. Majority of the RTA victims were male, between 20 to 40 years of age. Similar results were revealed in the previous studies conducted at various places [15] [16] [17] [19] [20] [22] [23] [24]. However, the contradictory with the study from Albania that highlighted the women were more victims in the RTAs [10]. Involvement of this age group could impact in productivity of the country. Increased mobility for work and other task compared to female and old age could be the reason for higher exposure in RTAs. Furthermore, more than half of the victims were educated up to secondary level and those with higher education were very less. It signifies that lack or no traffic awareness might have led to the road accidents. But in contrast, one of the study from India illustrated that majority of RTA cases were graduates followed by intermediate education [24]. Our findings revealed RTAs occurred higher in public holiday and previous study from India highlighted similar findings [17]. It could be the higher proportion of the people's movement for marketing and outing on holiday. Other reason might be the over speeding on the road because the traffic is lower in the 
public holidays. This study finding highlighted the RTAs took place in the morning. Similar finding was highlighted with the study conducted from India [16]. However, other studies have different findings that RTAs took place in the afternoon [9] and in the evening [15] [18]. In this study period, foggy morning which reduces the vision on the road might be the reason for higher accidents. Afternoon and evening time could be the long time driving which may be the reason for RTAs. This study also found that two wheeler vehicles were mainly exposed to accidents followed by four wheelers. Similar finding was also reported in a nation-wide population based survey conducted in Nepal [25] whereas six wheelers were found to be more involved than others in another study [26].

This study highlighted the lower limbs and head were the commonest sites of injuries. However, a systematic review conducted in Nepal illustrated both the lower and upper limbs as major site of injuries [7]. Other sites were upper limbs, trunk and body as well as facial parts. Head injury was the most common type of injury. Similar finding was revealed through the study conducted in western Nepal [18] and India [9] [15] [16] [19]. In addition, our study revealed the different types of injuries included cut injuries, laceration/abrasion, fractures and spinal injury. Among the fractures, lower extremities were the commonest site of fracture followed by spinal fracture. Other fractures included upper extremities, pelvis and ribs. Previous studies demonstrated the similar findings [15] [16] [20] [21] [23]. The proper use of helmets for motorcycle and scooter riders could be preventable for head injury.

Our findings revealed the significant association between young ages of drivers, driving speed, driving experience, ownership of vehicle with exposure to accidents. Previous literatures from different countries highlighted similar findings [9] [10] [11] [16] [17] [23]. Old and poor condition of vehicles was identified as other reason of the accidents. Literature from western Nepal also highlighted that old vehicles were responsible for higher number of accidents [18]. Our finding revealed increased year of experience of driver was associated with RTAs. This could be happened due to carelessness of the driver or lack of knowledge related to driving skills (ref). At the same time, opinion from the victims revealed the negligence of driver while driving was more common cause of the RTAs. A similar finding was revealed from systematic review that improper bus driving was one of the possible causes of accidents [7]. Previous study from Qatar also highlighted similar findings that careless driving was main cause of RTAs [27]. Increased knowledge and awareness related to RTAs among drivers and other peoples could reduce the accidents. Strong traffic rules against over speeding and careless driving may reduce the number of RTAs.

\section{Strength and Limitations}

The strength of the study may be that the findings of this research were based on the interview with not only RTA victims but also with the current drivers so that 
the actual factors were driven from both perspectives. There were no studies done prior to this although this was highly risk area for RTA so this could help in further researches and mitigate the incidents. Moreover, the findings of study can be applied to similar type of hilly district.

The fatal cases were not included in this study so the causes of mortality due to RTAs could not be gathered. Similarly, the study was conducted in small city so the findings may not be generalized to all cities.

\section{Conclusion}

Young age of the driver, over speed, experience of the driving, and long time driving in a day are the main factors associated with the exposure of RTAs. Careless driving, old and poor vehicle condition and low knowledge related to RTAs are other crucial causes of RTAs. Strong road traffic rules related to road safety and education for driver and other people related to RTAs is the urgent need to reduce the number of RTAs.

\section{Acknowledgements}

The authors are thankful to all the participants who provided their valuable information. Furthermore, we wish to specially thank the Director and staffs of hospitals namely: United Mission to Nepal, Tansen and Lumbini Medical College and Research Center, Pravas, Palpa in completion of this study.

\section{Funding}

There was no financial support from anywhere.

\section{Authors' Contribution}

Conceived and designed the experiments: VLS. Performed the experiments: VLS. Analyzed the data: VLS DNB KMS KBGC SP. Wrote the paper: VLS DNB KMS. Designed the structure, conducted analysis, data collection, interpretation and wrote the draft of the manuscript: VLS. Contributed final draft of manuscript: VLS DNB KBGC SP

\section{References}

[1] Lozano, R., Naghavi, M., Foreman, K., Lim, S., Shibuya, K., Aboyans, V., Abraham, J., Adair, T., Aggarwal, R., Ahn, S.Y., et al. (2013) Global and Regional Mortality from 235 Causes of Death for 20 Age Groups in 1990 and 2010: A Systematic Analysis for the Global Burden of Disease Study 2010. The Lancet, 380, 2095-2128. http://www.thelancet.com/journals/lancet/article/PIIS0140-6736(12)61728-0/fulltext https://doi.org/10.1016/S0140-6736(12)61728-0

[2] Naghavi, M., Wang, H., Lozano, R., Davis, A., Liang, X., Zhou, M., Vollset, S.E., Ozgoren, A.A., Abdalla, S. and Abd-Allah, F. (2015) Global, Regional, and National Age-Sex Specific All-Cause and Cause-Specific Mortality for 240 Causes of Death, 1990-2013: A Systematic Analysis for the Global Burden of Disease Study 2013. The Lancet, 385, 117-171. https://doi.org/10.1016/S0140-6736(14)61682-2 
http://www.thelancet.com/journals/lancet/article/PIIS0140-6736\%2814\%2961682-2/ fulltext

[3] World Health Organization (2013) Global Status Report on Road Safety 2013: Supporting a Decade of Action:

http://www.who.int/violence_injury_prevention/road_safety_status/2013/en/

[4] Zhang, X., Xiang, H., Jing, R. and Tu, Z. (2011) Road Traffic Injuries in the People's Republic of China, 1951-2008. Traffic injury prevention, 12, 614-620. https://doi.org/10.1080/15389588.2011.609925

[5] Jacobs, G., Aeron-Thomas, A. and Astrop, A. (2000) Estimating Global Road Fatalities. Transport Research Laboratory, Crowthorne.

http://citeseerx.ist.psu.edu/viewdoc/download?doi=10.1.1.174.5207\&rep=rep1\&type $=\mathrm{pdf}$

[6] WHO (2015) Ten Strategies for Keeping Children Safe on the Road. http://apps.who.int/iris/bitstream/10665/162176/1/WHO_NMH_NVI_15.3_eng.pdf ?ua $=1 \&$ rua $=1$

[7] Karkee, R. and Lee, A.H. (2016) Epidemiology of Road Traffic Injuries in Nepal, 2001-2013: Systematic Review and Secondary Data Analysis. BMJ Open, 6, e010757. http://bmjopen.bmj.com/content/bmjopen/6/4/e010757.full.pdf

[8] Thapa, A.J. (2013) Status Paper on Road Safety in Nepal. DDG, Department of Roads. http://www.dor.gov.np/documents/Status_Paper\%20_2013.pdf

[9] Singh, D., Singh, S.P., Kumaran, M. and Goel, S. (2015) Epidemiology of Road Traffic Accident Deaths in Children in Chandigarh Zone of North West India. Egyptian Journal of Forensic Sciences, 6, 255-260. https://doi.org/10.1016/j.ejfs.2015.01.008 http://www.sciencedirect.com/science/article/pii/S2090536X1500026X

[10] Qirjako, G., Burazeri, G., Hysa, B. and Roshi, E. (2008) Factors Associated with Fatal Traffic Accidents in Tirana, Albania: Cross-Sectional Study. Croatian Medical Journal, 49, 734-740. https://doi.org/10.3325/cmj.2008.49.734

https://www.ncbi.nlm.nih.gov/pmc/articles/PMC2621023/pdf/CroatMedJ_49_0734. pdf

[11] Rasool, F.A.A., Alekri, F.A., Nabi, H.A., Naiser, M.J., Shamlooh, N.M., Alnashaba, S.A., Alherz, Z.A., et al. (2015) Prevalence and Behavioral Risk Factors Associated with Road Traffic Accidents among Medical Students of Arabian Gulf University in Bahrain. International Journal of Medical Science and Public Health, 4, 933-938. https://www.ejmanager.com/fulltextpdf.php?mno=180127 https://doi.org/10.5455/ijmsph.2015.14022015189

[12] Singh, S.K. and Misra, A. (2004) Road Accident Analysis: A Case Study of Patna City. Urban Transport Journal, 2, 60-75.

http://home.iitk.ac.in/ sanjay/patnastudy.pdf

[13] Kakkar, R., Aggarwal, P., Kakkar, M., Deshpande, K. and Gupta, D. (2014) Road Traffic Accident: Retrospective Study. Indian Journal of Scientific Research, 5, 59-62.

https://pdfs.semanticscholar.org/0533/a27d0150c7b28af5161017270ccfef13ad1f.pdf

[14] Adhikari, G.P. (2016) Road Traffic Accidents (RTAs) Trends on Kathmandu-Bhaktapur Road after Addition of Lanes. Open Journal of Civil Engineering, 6, 388-396. https://doi.org/10.4236/ojce.2016.63033 https://file.scirp.org/pdf/OJCE_2016060114124501.pdf

[15] Neeraj, K., Sanjay, G., Atul, V. and Athavale, A. (2012) Epidemiological Study of Road Traffic Accident Cases Attending Tertiary Care Hospital in Bhopal, Madhya 
Pradesh. National Journal of Community Medicine, 3, 395-399.

http://njcmindia.org/uploads/3-3_395-399.pdf

[16] Manna, N., Mallik, S., Mandal, P.K., Chakraborty, D., Sardarjc, P.H. and Gupta, S. (2013) Epidemiological Factors of Road Traffic Accidents: A Study in a Tertiary Care Setting in India. Journal of Pakistan Medical Students, 3, 48-53.

[17] Jha, N., Srinivasa, D., Roy, G., Jagdish, S. and Minocha, R. (2004) Epidemiological Study of Road Traffic Accident Cases: A Study from South India. Indian Journal of Community Medicine, 29, 20-24. http://medind.nic.in/iaj/t04/i1/iajt04i1p20o.pdf

[18] Mishra, B., Sinha, N.D., Sukhla, S. and Sinha, A. (2010) Epidemiological Study of Road Traffic Accident Cases from Western Nepal. Indian Journal of Community Medicine: Official Publication of Indian Association of Preventive \& Social Medicine, 35, 115.

https://www.researchgate.net/publication/45097881_Epidemiological_Study_of_Ro ad_Traffic_Accident_Cases_from_Western_Nepal

[19] Honnungar, R.S., Aramani, S.C., Kumar, V.A., Kumar, A.T. and Jirli, P.S. (2011) An Epidemiological Survey of Fatal Road Traffic Accidents and Their Relationship with Head Injuries. Journal of Indian Academy of Forensic Medicine, 33, 135-137. http://medind.nic.in/jal/t11/i2/jalt11i2p135.pdf

[20] Singh, R., Singh, H.K., Gupta, S. and Kumar, Y. (2014) Pattern, Severity and Circumtances of Injuries Sustained in Road Traffic Accidents: A Tertiary Care Hospital-Based Study. Indian Journal of Community Medicine: Official Publication of Indian Association of Preventive \& Social Medicine, 39, 30.

https://www.ncbi.nlm.nih.gov/pmc/articles/PMC3968579/

[21] Nóbrega, L.M., Cavalcante, G.M., Lima, M.M., Madruga, R.C., Ramos-Jorge, M.L. and d'Avila, S. (2014) Prevalence of Facial Trauma and Associated Factors in Victims of Road Traffic Accidents. The American Journal of Emergency Medicine, 32, 1382-1386. http://www.ajemjournal.com/article/S0735-6757(14)00610-X/abstract https://doi.org/10.1016/j.ajem.2014.08.054

[22] Karim, M., Khan, A.W. and Farah, S. (2013) Economic Impact of Road Traffic Accident on Patients Attending at National Institute of Traumatology and Orthopedic Rehabilitation (NITOR), Dhaka. Ibrahim Cardiac Medical Journal, 1, 45-49. https://www.banglajol.info/index.php/ICMJ/article/view/13560/9758

[23] Bhuyan, P.J. and Ahmed, F. (2013) Road Traffic Accident: An Emerging Public Health Problem in Assam. Indian Journal of Community Medicine: Official Publication of Indian Association of Preventive \& Social Medicine, 38, 100. https://www.ncbi.nlm.nih.gov/pmc/articles/PMC3714936/

[24] Kumar, P. and Srinivasan, K. (2013) To Study the Socio Demographic Profile of Road Traffic Accident Victims in District Hospital, Karimnagar. International Journal of Research \& Development of Health, 1, 136-140. http://www.ijrdh.com/files/RTA\%20article\%206.pdf

[25] Nepal, S., Gupta, S., Wong, E.G., Gurung, S., Swaroop, M., Kushner, A.L. and Nwomeh, B.C. (2015) Burden of Road Traffic Injuries in Nepal: Results of a Countrywide Population-Based Survey. The Lancet, 385, S7. http://www.thelancet.com/journals/lancet/article/PIIS0140-6736(15)60802-9/fulltext https://doi.org/10.1016/S0140-6736(15)60802-9

[26] Choulagai, B., Ling, H., Sharma, P., Mishra, S., Ahmed, M. and Chand, P. (2015) Epidemiology of Road Traffic Accidents in Nepal: Data Review and Qualitative Analysis. SM Journal of Public Health \& Epidemiology, 1, 1014. 
[27] Bener, A. (2005) The Neglected Epidemic: Road Traffic Accidents in a Developing Country, State of Qatar. International Journal of Injury Control and Safety Promotion, 12, 45-47. https://www.ncbi.nlm.nih.gov/pubmed/15814375

https://doi.org/10.1080/1745730051233142225 